\title{
Análise de Viabilidade Técnica e Econômica da Utilização do Biogás Produzido em uma Estação de Tratamento de Esgoto do Recife como Combustível para Veículos Leves
}

\author{
Technical and Economic Viability Analysis of the Use of Biogas Produced at a Sewage \\ Treatment Plant in Recife as Fuel for Light Vehicles
}

\author{
Ayla Souza' ${ }^{1}$ orcid.org/0000-0001-7491-7768 \\ Sérgio Peres ${ }^{\mathbf{1}}$ (iD orcid.org/0000-0002-2235-3507 \\ ${ }^{1}$ Escola Politécnica de Pernambuco, Pós-graduação em Energias Renováveis, \\ Universidade de Pernambuco, Recife, Brasil. \\ E-mail da autora principal: Ayla Souza aylasouza@hotmail.com
}

\section{RESUMO}

As constantes oscilações dos preços dos combustíveis fósseis impactam consideravelmente na receita operacional de uma estação de tratamento de esgoto, além do consumo destes ocasionar grandes emissões de GEE. Em 2014 o setor de transportes brasileiro foi responsável por 40,1\% das emissões de gases do efeito estufa. A utilização do biogás obtido a partir da digestão anaeróbia da matéria orgânica presente nos efluentes domésticos é uma tecnologia consolidada internacionalmente devido ao ganho ambiental e à redução dos custos operacionais. O presente estudo descreve o tipo de tratamento e etapas às quais o efluente é submetido, as características do biogás gerado e o processo de conversão deste em biometano. São apresentados os custos comparativos entre a utilização do biometano e dos combustíveis fósseis no âmbito veicular. Neste contexto, foi analisada a viabilidade técnica e econômica do aproveitamento energético do biogás produzido em uma estação de tratamento de esgoto de grande porte, localizada na região metropolitana do Recife, em Pernambuco, como combustível veicular em virtude dos altos custos da frota utilizada na operação do sistema em questão. A solução proposta se mostrou viável, apresentando retorno financeiro e ganhos ambientais de grande relevância associados ao menor potencial em emissões de GEE.

PALAVRAS-CHAVE: Esgoto; Biogás; Biometano; Combustível Veicular;

\section{ABSTRACT}

In 2014, the Brazilian transport sector accounted for $40.1 \%$ of greenhouse gas emissions. The use of biogas obtained from the anaerobic digestion of organic matter present in domestic effluents is an internationally consolidated technology due to the environmental gain and the reduction of operating costs. The present study describes the type of treatment and stages which the effluent is submitted, the characteristics of the biogas generated and the conversion process of biomethane. The comparative costs of the use of biomethane and fossil fuels in the vehicular environment are presented. On this context, the technical and economic viability of the biogas produced at a large sewage treatment plant, located in the metropolitan area of Recife/Pernambuco as vehicular fuel due to the high costs of the fleet used in the proposed solution proved to be feasible, presenting financial returns and environmental gains of prominent relevance associated to the lower potential in GHG emissions.

KEY-WORDS: Sewer; Biogas; Biomethane; Vehicle Fuel; 
Análise de Viabilidade Técnica e Econômica da Utilização do Biogás Produzido em uma Estação de Tratamento de Esgoto do Recife como Combustível para Veículos Leves

\section{INTRODUÇÃO}

O fortalecimento mundial da corrente de incentivo à utilização de combustíveis oriundos de fontes renováveis, nos últimos anos, decorre principalmente da busca por recursos eficientes, de baixa emissão de carbono e que proporcionem segurança energética de fornecimento para garantir o crescimento sustentável das economias em todo o mundo. Neste contexto se faz necessária a criação de incentivos fiscais, tais como isenção de impostos, e de financiamentos com taxas de juros menores e mais convidativas visando a atração de investimentos voltados à geração de energia limpa.

O biometano é uma fonte renovável com grande potencial energético e pode contribuir para uma maior diversificação da matriz energética nacional. É amplamente utilizado como combustível veicular no cenário internacional. No Brasil, entretanto, a aplicação da tecnologia de injeção de biogás na rede de gás natural é recente visto que essa atividade foi regulamentada através da Resolução No 8, de 30 de janeiro de 2015, da Agência Nacional do Petróleo, Gás Natural e Biocombustíveis (ANP) [1].

$\mathrm{Na}$ estação de tratamento de esgoto em questão não é realizado o aproveitamento energético do biogás produzido. Este é conduzido ao "flare" para a queima, uma vez que $65 \%$ da sua composição é representada pelo $\mathrm{CH}_{4}$, gás cujo potencial de aquecimento global é 21 vezes superior ao do $\mathrm{CO}_{2}$ [2].

$\mathrm{O}$ presente estudo tem como objetivo propor o aproveitamento energético do biogás gerado no processo de tratamento de efluentes da estação de tratamento de esgoto em questão como combustível veicular e analisar a viabilidade econômica desta solução. A frota utilizada na operação de parte das unidades componentes do sistema de saneamento do Recife é composta por 300 veículos leves movidos à gasolina. Os elevados custos associados ao consumo deste combustível fóssil, cerca de $\mathrm{R} \$ 218.400,00 /$ mês, o relevante volume de produção de biogás previsto pelo projeto de ampliação da ETE, aproximadamente $6.400 \mathrm{Nm}^{3} / \mathrm{dia}$, e a grande contribuição do setor de transportes nas emissões causadoras do efeito estufa motivaram este estudo.

\section{CARACTERISTICAS DO EFLUENTE E DA UNIDADE DE TRATAMENTO}

Os esgotos sanitários são compostos basicamente por $99,9 \%$ de água e $0,1 \%$ de sólidos orgânicos e inorgânicos, em suspensão, dissolvidos e por micro-organismos. O tratamento de esgoto sanitário a partir de processos biológicos é caracterizado por reproduzir os processos naturais de estabilização e autodepuração de um corpo hídrico, após o lançamento de esgoto, em que matéria orgânica é convertida em materiais mineralizados inertes [3].

ETE's são unidades operacionais do sistema de esgotamento sanitário que removem as cargas poluentes do esgoto através de processos físicos, químicos ou biológicos, devolvendo o efluente tratado ao ambiente, em conformidade com os padrões exigidos pela legislação ambiental [4]. O sistema em estudo atende atualmente cerca de 200.000 habitantes e é por composto por uma rede coletora de mais de $200 \mathrm{~km}$ de extensão, 17 estações elevatórias e uma estação de tratamento com vazão média de entrada de $500 \mathrm{l} / \mathrm{s}$. Encontra-se em ampliação através da qual receberá a vazão média de $1000 \mathrm{l} / \mathrm{s}$ e realizará o processo de tratamento de efluentes composto pelas fases preliminar, primária e secundária.

O tratamento preliminar é caracterizado por um processo físico onde ocorre a remoção dos sólidos grosseiros e minerais, principalmente areia, através de grades de barras, peneiras e desarenadores. O tratamento preliminar objetiva a proteção dos dispositivos de transporte dos esgotos tais como bombas, tubulações e demais unidades componentes do sistema, bem como a dos corpos hídricos receptores através da remoção parcial da carga poluidora, contribuindo para melhorar o desempenho das unidades subsequentes do tratamento [5].

A etapa seguinte é o tratamento primário onde ocorre remoção parcial dos sólidos em suspensão sedimentáveis e dos sólidos flutuantes, como os óleos e graxas. Esta etapa é de grande importância, pois proporciona uma menor carga orgânica afluente à etapa de tratamento secundário cujo custo é mais elevado.

A NBR 12.209 [6] indica que o tratamento secundário visa, principalmente, a remoção da matéria orgânica composta pela fração dissolvida e pelos sólidos de sedimentabilidade mais lenta remanescentes dos processos primários. A 
principal característica do tratamento secundário é a inclusão de uma fase biológica, uma vez que a remoção da matéria orgânica ocorre em função de reações bioquímicas realizadas por microorganismos [7]. A formação do biogás se dá na fase secundária onde o contato dos microorganismos com a matéria orgânica contida no efluente é otimizado através do sistema anaeróbio.

Cerca de 50 a $80 \%$ do total de matéria orgânica que entra no sistema da estação de tratamento de esgoto é convertido em biogás, do qual pode ser aproveitado o potencial energético do metano [8]. O poder calorífico inferior do metano é $35.587,80 \mathrm{~kJ} / \mathrm{m}^{3}$ [9]. Adotou-se que o biogás produzido durante o processo teria em sua composição $65 \%$ de $\mathrm{CH}_{4}$, o que corresponde a um poder calorífico inferior de $23.027,40 \mathrm{~kJ} / \mathrm{m}^{3}$.

\section{PROCESSOS DE CONVERSÃO DA MATÉRIA ORGÂNICA}

A digestão anaeróbica da matéria orgânica envolve uma série de etapas diferentes de degradação que ocorrem sequencialmente e que dependem da atividade de pelo menos três grupos fisiológicos de organismos: as bactérias acidogênicas, acetogênicas e as arqueas metanogênicas [10].

A degradação da matéria orgânica ocorre em quatro etapas principais: hidrólise, acidogênese, acetogênese e metanogênese [11]. O início do processo se dá através da hidrólise onde o material particulado é convertido em compostos dissolvidos de menor peso molecular, os quais podem atravessar as paredes celulares das bactérias fermentativas. Nesta etapa as proteínas são convertidas em aminoácidos, os lipídeos em ácidos graxos e os carboidratos em açúcares.

A segunda etapa é a acidogênese na qual as bactérias fermentativas acidogênicas absorvem os compostos gerados durante a hidrólise, transformando-os em substâncias mais simples que posteriormente são excretadas ao meio. Os compostos produzidos compreendem ácidos orgânicos, álcoois, gás carbônico, hidrogênio, ácido sulfídrico e amônia. Esta etapa é muito importante para sistemas de tratamento anaeróbio pois se o oxigênio dissolvido, eventualmente presente, não fosse removido pelas bactérias acidogênicas facultativas poderia se tornar uma substância tóxica para as metanogênicas.

A terceira fase da digestão anaeróbia é a acetogênese, onde os ácidos orgânicos e álcoois produzidos na fase acidogênica são metabolizados pelas bactérias acetogênicas para produzir ácido acético, dióxido de carbono e hidrogênio.

$\mathrm{Na}$ quarta fase, chamada metanogênese, o metano é produzido a partir da conversão de acetato, hidrogênio e dióxido de carbono, principalmente, em metano e dióxido de carbono. Essa conversão é efetuada pelos microorganismos metanogênicos (arqueas metanogenicas), que desempenham função vital em ambientes anaeróbios, pois removem 0 excesso de hidrogênio e os produtos da fermentação que são oriundos de fases anteriores. Com isso é possível a redução da pressão parcial de hidrogênio do meio, o que torna possível as reações efetivadas pelas acetogênicas.

Simultaneamente à metanogênese ocorre a sulfetogênese, onde os compostos à base de enxofre são utilizados como aceptores de elétrons, durante a oxidação de compostos orgânicos. Neste processo os compostos sulfurados são reduzidos a sulfeto através da ação de um grupo de micro-organismos anaeróbios estritos, denominadas bactérias sulforedutoras.

O biogás é, por definição, uma mistura de gases gerados durante a digestão anaeróbia da matéria orgânica. Sua composição é variável, dependendo do tipo e concentração da matéria orgânica a ser digerida, das condições físicoquímicas no interior do digestor $(\mathrm{pH}$, alcalinidade, temperatura) e da presença de outros ânions, como o sulfato e o nitrato [12]. Os constituintes usualmente presentes no biogás gerado através de processos de digestão anaeróbia em digestores de lodo são metano, gás carbônico, monóxido de carbono, nitrogênio, hidrogênio, sulfeto de hidrogênio e oxigênio (Tabela 1). 
Análise de Viabilidade Técnica e Econômica da Utilização do Biogás Produzido em uma Estação de Tratamento de Esgoto do Recife como Combustível para Veículos Leves

Tabela 1: Composição típica do biogás gerado em digestores de lodo oriundo de Esgoto doméstico.

\begin{tabular}{l|l}
\hline \multicolumn{1}{c|}{ Parâmetro } & $\begin{array}{c}\text { Biogás de digestores } \\
\text { de lodo }\end{array}$ \\
\hline Metano (\%) & 60 à 70 \\
\hline Gás Carbônico (\%) & 20 à 40 \\
\hline Monóxido de Carbono (\%) & - \\
\hline Nitrogênio (\%) & $<2$ \\
\hline Hidrogênio (\%) & - \\
\hline Sulfeto de Hidrogênio (ppmv) & Até 1000 \\
\hline $\begin{array}{l}\text { Oxigênio (\%) } \\
\text { Fonte: [8]. }\end{array}$ & -45
\end{tabular}

\section{PURIFICAÇÃO DO BIOGÁS}

O biogás produzido é encaminhado ao sistema de purificação para a obtenção do biometano cuja composição varia de acordo com o uso pretendido. Em geral pode-se afirmar que, qualquer que seja a forma de utilização, é indispensável o controle rigoroso da desumidificação, dessulfurização, remoção de $\mathrm{CO}_{2}$ e a eliminação dos siloxanos tendo como objetivo o aumento do poder calorífico e maior vida útil dos equipamentos e demais componentes do sistema.

\subsection{Descrição do Processo}

O processo de beneficiamento e disponibilização do biogás proposto neste estudo teve como referências tecnologias amplamente utilizadas na Europa e as normas alemãs DWA-M 363 [13] e DWA-M 361 [14] para a utilização do biometano como combustível veicular em virtude da inexistência de legislação específica no Brasil.

O tratamento inicia-se com a captação do gás na saída do biodigestor. Posteriormente este é direcionado, através de um soprador, ao tanque de lavagem do biogás onde substâncias indesejáveis solúveis em água e demais sedimentos são capturados e eliminados [15].

A água contida no biogás pode condensar nas tubulações e causar corrosão devido à formação de gases ácidos. Em virtude disto, na etapa seguinte, o biogás passa por um tanque adsorvente preenchido com sílica gel $\left(\mathrm{SiO}_{2}\right)$ onde ocorrerá a remoção da umidade. Este processo ocorre à temperatura ambiente, pressões entre 6 e 10 Bar e ponto de orvalho abaixo de $-60^{\circ} \mathrm{C}$. Este método possui elevada capacidade de adsorção de água, permite a reutilização dos adsorventes através da regeneração dos mesmos por aquecimento ou redução de pressão e possui um baixo risco de corrosão nos equipamentos, uma vez que não há necessidade de substâncias químicas adicionais no processo [16].

A etapa seguinte destina-se à remoção de $\mathrm{H}_{2} \mathrm{~S}$ e siloxanos pois, após a combustão, estas substâncias se acumulam nas paredes dos motores causando corrosão e incrustações nas superfícies expostas e consequente redução da vida útil e eficiência destes equipamentos.

Os siloxanos são compostos oriundos de produtos farmacêuticos, cosméticos, de higiene pessoal, e, agentes de limpeza, por isso é comumente encontrado em esgotos domésticos [17]. A dessulfurização é feita através de um processo de adsorção no qual as moléculas de compostos orgânicos voláteis entram em contato com a superfície de um adsorvente sólido e se ligam via forças moleculares fracas. A superfície de um adsorvente inclui todas as áreas acessíveis e pode, portanto, ser extensiva a sólidos que incorporam uma rede interna de poros, incluindo aqueles com diâmetros de dimensões moleculares [11]. Para o sistema proposto foi considerado a remoção do $\mathrm{H}_{2} \mathrm{~S}$ pela adsorção através de um filtro de carvão ativado.

A remoção do $\mathrm{H}_{2} \mathrm{~S}$ e siloxanos ocorre, preferencialmente, entre 10 e $70^{\circ} \mathrm{C}$ e se dá por meio da oxidação catalítica na estrutura porosa do carvão, onde o $\mathrm{H}_{2} \mathrm{~S}$ é convertido em enxofre elementar e posteriormente adsorvido nos microporos do carvão. Finalizada esta fase o biogás apresentará concentrações de $\mathrm{H}_{2} \mathrm{~S}$ inferiores à 1 ppm [18] e de siloxanos na ordem de $0,1 \mathrm{mg} / \mathrm{m}^{3}$ [19].

Em continuidade ao processo de beneficiamento do biogás se faz necessária a remoção do $\mathrm{CO}_{2}$ visando o aumento do percentual de metano na mistura e, consequentemente, do poder calorífico. Para tal finalidade foi adotado o sistema de membranas poliméricas que trabalham por diferencial de pressão à temperatura ambiente. O biogás é comprimido na faixa de 6 a 20 bar, a depender da necessidade específica do projeto [20]. Após ser comprimido é direcionado ao processo de separação de gases por membranas poliméricas em um estágio que consiste na passagem do biogás por um módulo onde $\mathrm{O}_{\mathrm{CO}_{2}}$ permeia a membrana de alta seletividade e $\quad \mathrm{C}^{\mathrm{CH}_{4}}$ segue a corrente do concentrado. A eficiência do processo depende de características como a seletividade da membrana, 
sua permeabilidade, tempo de vida, temperatura de operação e faixa de umidade [16]. O sistema proposto proporciona a remoção de até $99 \%$ do $\mathrm{CO}_{2}$ contido no biogás [15].

A ANP publicou em janeiro de 2015 a Resolução $n^{\circ} 8 / 2015$ que estabelece as especificações para o biometano no Brasil. Após com concluído o processo de purificação, o biometano deve apresentar em sua composição o mínimo de 96,5\% de $\mathrm{CH}_{4}$ [1] (Tabela 2).

Tabela 2: Composição típica do biogás gerado em digestores de lodo oriundo de Esgoto doméstico.

\begin{tabular}{l|c}
\multicolumn{1}{c|}{ Parâmetro } & Limite \\
\hline $\mathrm{CH}_{4}$ mínimo (\%mol) & 96,5 \\
\hline $\mathrm{O}_{2}$ máximo $(\% \mathrm{~mol})$ & 0,5 \\
\hline $\mathrm{CO}_{2}$ máximo $(\% \mathrm{~mol})$ & 3 \\
\hline $\mathrm{CO}_{2}+\mathrm{O}_{2}+\mathrm{N}_{2}$ máximo $(\% \mathrm{~mol})$ & 3,5 \\
\hline Enxofre Total máximo $\left(\mathrm{mg} / \mathrm{m}^{3}\right)$ & 70 \\
\hline $\mathrm{H} 2 \mathrm{~S}\left(\mathrm{mg} / \mathrm{m}^{3}\right)$ & 10 \\
\hline Ponto de Orvalho da & \\
água máximo à $1 \mathrm{~atm}\left({ }^{\circ} \mathrm{C}\right)$ & -45
\end{tabular}

Fonte: [1].

\subsection{Características do Sistema}

O sistema de purificação do biogás proposto para obtenção do biometano é composto por um soprador, tanque lavador de gás, tanque removedor de umidade, filtro de carvão ativado para remoção de $\mathrm{H}_{2} \mathrm{~S}$ e siloxanos, compressor, circuito de refrigeração de utilidades, membrana polimérica em um estágio para separação do dióxido de carbono do metano e acessórios afins [15].

A vazão de entrada prevista no projeto de ampliação da ETE estudada será aproximadamente $270 \mathrm{Nm}^{3} / \mathrm{h}$ de biogás, dos quais $65 \%$ é composto por metano. A vazão de saída do biometano será aproximadamente 175 $\mathrm{Nm}^{3} / \mathrm{h}$. O sistema de purificação de biogás proposto pelas empresas Albrecht e Pentair Flow \& Filtration Solutions assegura $99 \%$ de pureza [15] [21].

Devido às oscilações da produção e visando o aproveitamento contínuo se faz necessário o armazenamento do biometano. O volume de armazenamento, em alta pressão (1 a 10 bar), deve corresponder a cerca de $30 \%$ a $50 \%$ do volume diário de biogás gerado [13]. Foi adotado o orçamento do gasômetro de membrana dupla fabricado pela empresa austríaca TECON, cujo volume se refere a $30 \%$ da produção diária de biogás, aproximadamente $2.100 \mathrm{~m}^{3}$ [22].

Tendo em vista questões de segurança, manutenção do sistema e controle entre o volume produzido e consumido foi considerada a implantação de uma linha paralela de gás direcionada um queimador. Foram previstos no sistema principal e secundário de beneficiamento do biogás medidores de vazão, temperatura, pressão e concentração do gás para monitorar a produção, qualidade e principais características do processo, bem como itens de segurança, tais como selo hidráulico, válvulas corta-chamas e de alívio.

A frota utilizada na operação da estação de tratamento de esgoto em questão e demais unidades participantes da concessão é composta por 300 veículos leves cuja demanda individual mensal é de $2.000 \mathrm{~km}$. Tratam-se de veículos com motor 1.0 , cuja potência é de $75 \mathrm{cv}$, pertencentes à categoria flex que atualmente utilizam gasolina como combustível. Foi considerada a adaptação do motor padrão à gasolina para operar adicionalmente com um sistema movido à biometano. Tal adaptação é feita através da instalação de um kit de conversão de $5^{\circ}$ geração para gás natural cujas características são semelhantes às do biometano. O sistema de controle favorece a operação com biometano e a gasolina só é utilizada para a partida e o aquecimento do motor ou quando o nível de gás estiver baixo.

Na Europa é consolidada a fabricação de veículos leves híbridos permitindo tanto a utilização do biometano e gás natural, quanto gasolina. O catálogo produzido pela Natural \& bio Gas Vehicle Association (NGVA), organização representante das empresas e associações da Europa envolvidos na utilização do gás natural e biometano como combustível para veículos, apresenta características como potência, consumo de combustível e custo destes [23]. Foram analisados modelos semelhantes em potência aos utilizados no estudo em questão e obteve-se a média de consumo variando entre 20,7 a 22,8 $\mathrm{km} / \mathrm{m}^{3}$. No entanto, devido aos veículos serem adaptados com kits de conversão, foi considerado o rendimento menor ao praticado por veículos híbridos de fábrica. Adotou-se o consumo médio de $17 \mathrm{~km} / \mathrm{m}^{3}$ pois este foi o valor obtido através do acompanhamento de 40 veículos leves 
Análise de Viabilidade Técnica e Econômica da Utilização do Biogás Produzido em uma Estação de Tratamento de Esgoto do Recife como Combustível para Veículos Leves

adaptados para uso do biometano produzido na

usina do Consórcio Verde localizada em Montenegro, no Rio Grande do Sul [24].

O abastecimento é feito através de um sistema fechado, ou seja, conexão estanque do acoplamento do bico ao tanque do veículo. Esse tipo de atividade dura aproximadamente de 1 à 5 minutos, mesmo tempo necessário para combustíveis líquidos.

\section{ANÁLISE DE CUSTOS}

Para o cálculo de viabilidade econômica realizou-se um levantamento dos custos referentes aos equipamentos necessários ao sistema proposto para o beneficiamento do biogás. Devido à escassez de dados relevantes na literatura para este tipo de análise foram adotados os índices de desempenho internacionais da NGVA [23] e orçamentos das empresas especializadas na área, nacionais e internacionais, bem como projeções de preços baseadas na inflação.

Adotou-se como premissa que os custos referentes à aquisição e implantação do empreendimento em questão serão assumidos através de capital próprio da empresa responsável pela concessão da estação de tratamento de esgoto em estudo, desconsiderando-se assim a necessidade de financiamento dos mesmos.

As obras civis e projetos, por tratarem de pequenas adaptações na estrutura existente na ETE, foram orçadas adotando-se $1 \%$ do valor total da planta. Para montagem e custos referentes à reposição dos materiais de consumo, como carvão ativado e sílica gel, foi adotado $0,5 \%$ do valor total da planta tendo como base informações fornecidas por especialistas na área.

O custo de manutenção para plantas de biogás varia entre 1 a $2 \%$ do custo de investimento [25]. Adotou-se $2 \%$ ao ano para o caso em estudo. Para operação do sistema considerou-se o incremento de dois funcionários no efetivo da ETE, uma vez esta já se encontra em funcionamento.

De acordo com a Pentair Flow \& Filtration Solutions, empresa especializada em fornecimento de sistemas de beneficiamento do biogás, pode-se estimar 0 percentual de aproximadamente $5 \%$ ao ano do valor do empreendimento para itens consumíveis como a sílica gel, o carvão ativado e a membrana polimérica [15].
A Companhia Pernambucana de Gás (COPERGÁS), tendo como objetivo de aumentar as conversões de veículos para gás natural veicular (GNV) no estado, iniciou uma campanha de estímulo ao uso deste combustível concedendo um bônus de $\mathrm{R} \$ 1.000,00$ para a instalação do kit de conversão de $5^{\circ}$ geração[26]. Adotada esta premissa, o custo do kit de conversão utilizado nos veículos leves, usufruindo da bonificação, foi de $R \$ 3.400,00 /$ veículo. Foi considerado o valor anual de $R \$ 200,00 /$ veículo para a manutenção dos kits e uma vida útil de cerca de $300.000 \mathrm{~km}$ [27]. Assim sendo, para a utilização de $2.000 \mathrm{~km} / \mathrm{mês} /$ veículo, a durabilidade do kit de conversão é de aproximadamente 12,5 anos, período também considerado como vida útil do projeto. Os custos inerentes ao sistema de beneficiamento do biogás totalizaram $\mathrm{R} \$ 11.031 .125,31$ (Tabela 3):

Tabela 3: Custos do sistema de beneficiamento do biogás.

\begin{tabular}{l|l}
\hline \multicolumn{1}{c|}{ Item } & \multicolumn{1}{c}{$\begin{array}{c}\text { Custo para 12,5 anos } \\
\text { (R\$) }\end{array}$} \\
\hline $\begin{array}{l}\text { Sistema de purificação e } \\
\text { armazenamento }\end{array}$ & $3.227 .397,36$ \\
\hline Flare, tubulações e medidores & $161.010,00$ \\
\hline Projetos e obras civis & $32.273,97$ \\
\hline Montagem do sistema & $16.000,00$ \\
\hline Kits de 50 geração & $1.020 .000,00$ \\
\hline Manutenção do sistema & $1.125 .886,98$ \\
\hline Operação & $1.587 .280,77$ \\
\hline Consumíveis & $2.969 .870,21$ \\
\hline Manutenção dos kits & $1.046 .558,75$ \\
\hline Custo total do sistema & $\mathbf{1 1 . 0 3 1 . 1 2 5 , 3 1}$ \\
\hline Fonte: A autora &
\end{tabular}

Fonte: $A$ autora.

Foi feita a projeção dos custos para os 12,5 anos seguintes tendo em vista os respectivos ajustes necessários aos itens inflacionáveis pertencentes ao sistema de beneficiamento do biogás como mão de obra para a operação, itens consumíveis, manutenção do sistema e dos kits de conversão de $5^{\circ}$ geração, bem como os preços dos combustíveis convencionais. A inflação adotada para as correções foi de $5,6 \%$ ao ano, valor que representa a média dos últimos 10 anos, segundo o Instituto Brasileiro de Geografia e Estatística (IBGE) [28].

Obteve-se o valor de $R \$ 0,638 / \mathrm{m} 3$ de biometano produzido na ETE em estudo. As cotações médias do gás natural, gasolina e álcool adotadas foram obtidas através de consultas ao 
site da ANP no período de 11 à 17 de dezembro de 2016. Para o custo total do GNV ao logo do período de 12,5 anos foram consideradas as inclusões dos valores referentes à aquisição dos kits de conversão de $5^{\circ}$ geração, bem como a manutenção anual destes.

A receita do projeto é vinculada ao comparativo entre o custo do biometano versus 0 custo referente ao consumo equivalente dos combustíveis convencionais no referido período (Quadro1 e 2).

Quadro 1: Comparativo entre o consumo e custos entre os combustíveis convencionais e o biometano.

\begin{tabular}{|c|c|c|c|}
\hline Combustível & $\begin{array}{c}\mathrm{km} / \mathrm{I} \\
\mathrm{km} / \mathrm{m}^{3}\end{array}$ & $\begin{array}{c}\mathbf{R} \$ / / \\
\mathbf{R} \$ / \mathbf{m}^{3} \\
\end{array}$ & $\begin{array}{c}\text { Consumo } \\
\text { anual }\end{array}$ \\
\hline Etanol & 5,96 & 2,95 & $1.208 .053,69$ \\
\hline Gasolina & 10 & 3,64 & $720.000,00$ \\
\hline GNV & 13 & 2,07 & $553.846,15$ \\
\hline Biometano & 17 & 0,638 & $423.529,41$ \\
\hline
\end{tabular}

Fonte: A autora.

Quadro 2:Comparativo doscustos e payback entre os combustíveis convencionais e o biometano.

\begin{tabular}{|l|l|l|l}
\hline Combustível & $\begin{array}{l}\text { Custo 12,5 } \\
\text { anos (R\$) }\end{array}$ & $\begin{array}{l}\text { Economia } \\
\mathbf{1 2 , 5} \text { anos } \\
\text { (R\$) }\end{array}$ & $\begin{array}{l}\text { Pay } \\
\text { back } \\
\text { (anos) }\end{array}$ \\
\hline Etanol & $31.637 .071,17$ & $20.605 .945,86$ & 5,25 \\
\hline Gasolina & $23.234 .504,97$ & $12.203 .379,66$ & 6.83 \\
\hline GNV & $22.054 .220,82$ & $11.023 .095,51$ & 7,01 \\
\hline Biometano & $11.031 .125,31$ & NA & NA \\
\hline
\end{tabular}

Foi considerado $80 \%$ do volume de biogás previsto em projeto em virtude da oscilação de produção e paralisações decorrentes de manutenções do sistema. A análise de viabilidade proposta é voltada para a utilização do biometano como combustível em veículos leves, esta corresponde a aproximadamente $25 \%$ do volume total produzido, cerca de $1.180 \mathrm{~m}^{3} /$ dia. Para os demais $75 \%$, aproximadamente $3.560 \mathrm{~m}^{3} /$ dia, propõe-se o aproveitamento na frota composta por 78 veículos pesados responsáveis pela operação da ETE e outras unidades pertencentes à concessão. Segundo dados apresentados pela Scania, o rendimento do biometano para veículos pesados é de $2,02 \mathrm{~km} / \mathrm{m}^{3}$ [29]. Assim sendo o volume de $3.560 \mathrm{~m}^{3} /$ dia proporciona uma autonomia de cerca de $1.760 \mathrm{~km} / \mathrm{dia}$. Considerando-se que cada veículo pesado utilizado na operação das unidades de tratamento de esgoto percorre cerca de $35 \mathrm{~km} / \mathrm{dia}$, o volume anteriormente citado, $3.560 \mathrm{~m}^{3} / \mathrm{dia}$, seria suficiente para abastecer 50 veículos de grande porte componentes da frota em questão. Esta opção não foi detalhada neste estudo em virtude da escassez de referências bibliográficas acerca do tema e, consequentemente, da dificuldade em precificar os kits de conversão para veículos de grande porte uma vez que esta alternativa não é consolidada no Brasil.

\section{Considerações Finais}

O aproveitamento do biogás obtido através do tratamento de efluentes da ETE em questão mostrou-se técnica e economicamente viável e, para o período de 12,5 anos detalhado na Tabela 4, apresentou o payback em 5,25, 6,83 e 7,01 anos quando comparado ao custo referente ao consumo de etanol, gasolina e GNV, respectivamente. A solução proposta traz consigo, além do retorno financeiro, ganhos ambientais de grande relevância devido ao menor potencial em emissões de poluentes causadores do efeito estufa. Outros fatores importantes são a independência adquirida frente aos combustíveis convencionalmente utilizados e suas constantes altas de preço, bem como o incremento de receita associado à economia gerada pelo consumo do biometano.

\section{REFERÊNCIAS}

[1] AGÊNCIA NACIONAL DO PETRÓLEO (Brasil). Resolução ANP No 08, DE 30.1.2015, DOU 2.2.2015. Brasília: Agência Nacional do Petróleo, Gás Natural e Biocombustíveis, 2015.

[2] INTERGOVERNMENTAL PANEL ON CLIMATE CHANGE (IPCC), 2013. Disponível em: http://www.climatechange2013.org/images/ report/WG1AR5_ALL_FINAL.pdf. Acesso em: 08 jun. 2016.

[3] Chernicharo, C. A. L. Princípios do tratamento biológico de águas residuárias: Reatores Anaeróbios. 2. ed. Belo Horizonte: Departamento de engenharia Sanitária e Ambiental, 2007. p. 379-380.

[4] CASAN. Companhia Catarinense de Águas e Saneamento. 2012. Disponível em: http://www.casan.com.br/menu-

DOI: $10.25286 /$ repa.v4i2.1221 
Análise de Viabilidade Técnica e Econômica da Utilização do Biogás Produzido em uma Estação de Tratamento de Esgoto do Recife como Combustível para Veículos Leves

conteudo/index/url/ete-estacao-de-

tratamento-de- esgotos-sanitarios\#0. Acesso em: 25 ago. 2016.

[5] JORDÃO, E. P.; PESSÔ A, C. A. Tratamento de Esgotos Domésticos. 6. ed. Rio de Janeiro: ABES, 2011. p. 969.

[6] ASSOCIAÇÃO BRASILEIRA DE NORMAS TÉCNICAS. NBR 12.209: Projeto de estações de tratamento de esgoto sanitário. Rio de Janeiro: ABNT, 2011.

[7] VON SPERLING, M. Princípios do Tratamento Biológico de Águas Residuárias Introdução à Qualidade das Águas e ao Tratamento de Esgotos. 3. ed. Belo Horizonte: Ed. UFMG, 2005. 452 p. v. 1.

[8] LOBATO, L. C. D. S. Aproveitamento Energético de Biogás Gerado em Reatores UASB Tratando Esgoto Doméstico. 2011. 187 f. Tese (Doutorado em Saneamento, Meio Ambiente e Recursos Hídricos) - Programa de Pós-graduação em Engenharia Sanitária e Ambiental, Universidade Federal de Minas Gerais, Belo Horizonte, 2011.

[9] LIMA, D. M. F. Influência da razão de recirculação na produção de hidrogênio em reator de leito fixo. 2005. $109 \mathrm{f}$. Dissertação (Mestrado em Engenharia Hidráulica e Saneamento) - Escola de Engenharia de São Carlos, Universidade de São Paulo, São Paulo, 2005.

[10] KHALID, A. et al. The anaerobic digestion of solid organic waste. Waste

Management, v. 31. p. 1737-1744, 2011.

[11] CHERNICHARO, C. A. L. E. A. Alternativas para o controle de emissões odorantes em reatores anaeróbios tratando esgoto doméstico. Engenharia Sanitária Ambiental, v. 15, p. 229-236, 2010.

[12] NOYOLA, A.; MORGAN-SAGASTUME, J. M.; LÓPEZ-HERNÁNDEZ, J. E. Treatment of Biogas Produced in Anaerobic Reactors for Domestic Wastewater: Odour Control and Energy/Resource Recovery. Reviews in Environmental Sciences and Biotechnology, v. 5, p. 93-114, 2006.

[13] DWA. Normas e Recomendações Técnicas DWA-M 363: Origem, Tratamento e Utilização do Biogás. [S.I.]: Deutsche Vereinigung für Wasserwirtschaft, Abwasser und Abfall e. V. Alemanha, 2010. p. 72.
[14] DWA. Normas e Recomendações Técnicas DWA-M 361PT: Tratamento de Biogás. [S. I.]: Deutsche Vereinigung für Wasserwirtschaft, Abwasser und Abfall e.V.. Alemanha,2011. p. 40.

[15] PENTAIR FLOW \& FILTRATION SOLUTIONS. Cotação para Sistema de Purificação do biogás. Irlanda: Pentair Flow \& Filtration Solutions, 2016.

[16] SECRETÁRIA NACIONAL DE SANEAMENTO AMBIENTAL, PROBIOGÁS (Brasil). Guia Técnico de Aproveitamento Energético de Biogás em Estações de Tratamento de Esgoto. Brasília: Ministério das Cidades, 2015. p.99, 106.

[17] GRAIVER, D.; FARMINER, K.W.; NARAYAN, R. A review of the fate and effects of silicones in the environment. Journal of Polymers and the Environment, v. 11, n. 4, p. 129-136, 2003.

[18] BIO-METHANE REGIONS. Introduction to the Production of Biomethane from Biogas. A Guide for England and Wales. [S.I.]: 2013.

[19] ROSSOL, D.; SCHMELZ, K. G.; HOHMANN, R. Siloxane im Faulgas. KA - Abwasser, Abfall, v. 50, n. 8, p. 1043, 2003.

[20] BAUER, F. et al. Biogas upgrading Review of commercial technologies, Svenskt Gastekniskt Center AB, Malmö. 2013.

[21] ALBRECHT. Cotação para Sistema de Purificação do biogás. Joinville: Albrecht Equipamentos Industriais, 2016.

[22] TECON. Cotação para Sistema de Armazenamento do biogás. Áustria: Textile Constructions G.m.b.H, 2016.

[23] NGVA, Vehicle Catalogue. NGVA - Natural \& bio Gas Vehicle Association. Europe, p. 4-8, 2016.

[24] AUTO INFORME. Sistema de Levantamento de Preços. 2016. Disponível em: http://www.autoinforme.com.br/fezes-deanimais-e-residuos-movem-onibus-scania/. Acesso em: 11 jun. 2018.

[25] POSTEL, J. et al. Tecnologia de Usinas para Produção de Biogás. In: (FNR), F. N. R. E. V. Guia Prático do Biogás: Geração e 
Utilização. Alemanha: FNR, 2010. p. 234.

\section{[26] COPERGÁS. Companhia Pernambucana} de Gás. 2015. Disponível em:

https://www.copergas.com.br/copergas-dabonus-de-r-1-mil-para-converter-veiculosa-gnv/\#.WFI3yzv7XCd. Acesso em: 11 jul. 2016.

[27] ALPHA GÁS NATURAL. Convertedora e Mecânica Geral. 2014. Disponível em: https://alphagasnatural.wordpress.com/not icias/. Acesso em: 11 jun. 2018.

[28] CARNEIRO, L. Jornal O Globo. 2015. Disponível em: http://oglobo.globo.com/economia/inflacao -fecha-2014-em-641-fica-abaixo-do-tetoda-meta-15004977. Acesso em: 10 set. 2016.

[29] SCANIA. Mobilidade Urbana com Gás Natural e Biometano. [apresentação] 2015. Disponível em: http://www.mobilize.org.br/midias/pesquis as/novo-onibus-movido-a-biometanognvda-scania.pdf. Acesso em: 11 jun. 2018. 